\title{
Review on Potential Targeted Therapies for Triple Negative Breast Cancer
}

\author{
Nurul Issttifa lyah Aminuddin1, Raihana Edros ${ }^{1}$ and Rajaletchumy Veloo Kutty1,2, \\ ${ }^{1}$ Faculty of Chemical and Process Engineering Technology, Universiti Malaysia Pahang, 26300 Gambang, Pahang, Malaysia. \\ ${ }^{2}$ Center of Excellence for Advanced Research in Fluid Flow, Universiti Malaysia Pahang, 26300 Gambnag, Pahang, Malaysia.
}

\begin{abstract}
Triple negative breast cancer (TNBC) is a very aggressive type of cancer. TNBC is not just a single type of disease to be cured, but it consists of 6 subtypes which are basal-like 1 and 2, immunomodulatory, mesenchymal, mesenchymal stem- like and luminar androgen receptor. These subtypes has diverse characteristics, which hold potential opportunity for targeted treatment. Lack of molecular targets for triple negative tumor lead to limited targeted therapies for TNBC. Therefore, effective targeted therapies are urgently needed for TNBC. This paper will highlight on the potential targets in TNBC and treatment options that are currently under clinical application.
\end{abstract}

\section{KEYWORDS}

Targeted therapies, triple negative breast cancer.

\section{INTRODUCTION}

Breast cancer is the second leading of cancer death in woman after lung cancer (Jamdade et al., 2015). Fortunately, with advances screening and treatment, survival rates have been improves significantly. Immunohistochemistry classification was performed to determine molecular subtype of breast cancer based on the presence of biomarkers such as estrogen receptor (ER), progesterone receptor (PR) and human epidermal growth factor receptor 2 (HER2) as stated in Table 1. The major reported subtypes of breast cancer are luminal A, luminal B, HER2 enriched and basal like (Dai et al. 2016). As the study improves, researchers identify another molecular subtype such as normal breast cell-like and claudin low (Kondov et al., 2018). Knowledge about the molecular subtypes are importants to determine the disease outcome and treatment selection for breast cancer.

Breast cancer subtypes such as luminal A/B, HER2 enriched, normal breast cell-like with the presence of ER, PR and HER2 usually has standard treatment such hormone theraphy or HER2 targeted theraphy. However, for breast cancer subtypes with absence of ER, PR and HER2 the treatment remains challenging as chemotherapy still primary option for treatment (Jhan \& Andrechek, 2017). Triple negative breast cancer (TNBC) is a molecular subtype of breast cancer with the absence of ER, PR and HER2. TNBC accounts for approximately 10\%-15\% of diagnosed breast cancer (Lebert et al. 2018). Eventough TNBC is only minority in breast cancer, it has worse prognosis, aggressive tumor and distant recurrence which is worse as compared to the other subtype breast cancer (Prasad et al., 2016). TNBC also has higher chance to develop metastasis that appear in brain and lung (Mehanna, Haddad, Eid, Lambertini, \& Kourie, 2019).

Table 1. Molecular subtype of breast cancer (+/- shows status of receptor) (Dai et al., 2016).

\begin{tabular}{|lll|}
\hline Subtype & Expression of Receptor & Tumor Grade \\
\hline Luminal A & ER+,PR+,HER2- & Low \\
\hline Luminal B & ER+/-,PR+/-,HER2+/- & Intermediate/High \\
\hline HER 2 & ER-,PR-,HER2+ & High \\
\hline Normal breast-cell like & ER+,PR+,HER2- & Intermediate/High \\
\hline Claudin low & Lacks expression of claudin protein. & High \\
\hline Basal like & ER-,HER2- & High \\
\hline
\end{tabular}

Based on Table 1, there are similarity between the expression of basal like and claudin low with TNBC. TNBC is often associated with basal like subtype due to negative expression of ER, PR and HER2, although the two do not completely overlap. Approximately $70 \%$ of the basal like cancers are TNBC and $71 \%$ to $91 \%$ of TNBC belong to basal like cancers (Penault-Llorca \& Viale 2012). Claudin low also display similar receptor expression as TNBC, approximately about 25\% to 39\% cases of triple negative breast cancers are claudin low (Dias et al. 2017; Peddi et al. 2012). To explore more potential therapeutic treatment for TNBC, more in-depth study about TNBC subtypes have been examined. There are 6 molecular subtypes of TNBC according to their gene expression profile as stated in Table 2 (Lehmann et al., 2011). 
Table 2. Subtype of TNBC based on gense exxpression profilling (Ahn, Kim, Kim, \& Jeong, 2016; Lehmann et al., 2011)

\begin{tabular}{|ll|}
\hline Subtype & Gene Expression Profile \\
\hline Basal-like 1 (BL1) & High expression of genes involved in cell cycle and DNA repair \\
\hline Basal-like 2 (BL2) & High expression of genes involved in growth factor signalling genes \\
\hline Immunomodulatory (IM) & Enriched with gene for immune cell processes \\
\hline Mesenchymal (M) & High expression of genes associated with cell motility \\
\hline Mesenchymal stem- like (MSL) & $\begin{array}{l}\text { Enriched gene related growth factor signalling and low levels of } \\
\text { proliferating genes }\end{array}$ \\
\hline $\begin{array}{l}\text { Luminal androgen receptor } \\
\text { (LAR) }\end{array}$ & $\begin{array}{l}\text { High expression of androgen receptor involved in signalling and } \\
\text { downstream pathways. }\end{array}$ \\
\hline
\end{tabular}

Limited treatment in TNBC due to the of absence of receptor, may worsen the clinical course for TNBC patients (Bollinger et al., 2013). Hence, chemotherapy, surgery or a combination of both are the only treatment approaches for TNBC. However, there is an issue with the current treatment which is some patients showing resistant with the current chemotherapy regime (Johnson et al. 2013). Also more studies are needed for the chemotherapeutic agents in order to reduce toxicity as it may cause life threatening side effects (Kutty \& Feng, 2013). Deeper knowledge about TNBC from gene expression profile provides insight to identify treatment strategies to treat TNBC patients effectively. This review presents recent therapeutic options for the treatment of TNBC based on the several subtype of TNBC.

\section{TARGETED THERAPEUTIC OPTIONS FOR TNBC}

\section{Poly ADP-ribose polymerase (PARP) inhibitor}

TNBC is associated with BRCA mutant tumor cells, this interesting link between TNBC tumours, basal like cancer and BRCA1 germline mutation may contribute to a treatment option for TNBC which is by using a PARP inhibitor. Approximately, 71\% of BRCA1 mutation breast cancer are TNBC (Mahfoudh et al., 2019). Basal like breast cancer has shown defects in DNA double-strand break repair, derived from BRCA1 mutation (Ismail-Khan \& Bui 2010). The BRCA1 helps maintaining the DNA stability, thus dysfunction of BRCA1 disturbs the ability of the cells to recover by reducing the DNA repair capacity (Desroches et al., 2015). PARP is an essential enzyme for the synthesis and repair of DNA (Lehmann et al., 2011). When DNA damage occurs, PARP is inhibited, breaks in double-strand DNA will assemble and repaired via homologous recombination. In order for the homologous recombination to function correctly both BRCA1 and BRCA2 are needed. Therefore, for tumor cell lines that lack the functional BRCA1 expression are sensitive to PARP inhibitors, leading to cell apoptosis (Wahba \& El-Hadaad 2015).

There are currently several PARP inhibitors in clinical trial that hold brighter future for the TNBC treatment. (Robson et al., 2017) investigated randomized phase III clinical study comparing PARP inhibitor olaparib monotherapy with standard chemotherapy in metastatic BRCA germline mutation patients. Patients receiving olaparib monotherapy had longer median progression free survival compared with standard chemotherapy ( 7 months versus 4.2 months). The overall response rate for olaparib was $59.9 \%$ and $28.8 \%$ in the standard chemotharapy group. Olaparib inhibitor provide better treatment with longer progression free survival and $42 \%$ lower risk of disease progression compared to standard chemotherapy.

Another inhibitor that is currently being studied against TNBC is veliparib. Study by (Rugo et al., 2016) state that the combination treatment of veliparib and carboplatin to chemotherapy increase the pathological complete response (pCR) rate to TNBC patients. Patients will received either combination of chemotherapy and inhibitor or chemotherapy alone. Based on the result, the pCR was $51 \%$ for standard chemotherapy-veliparib-carboplatin while $26 \%$ for standard chemotherapy. Combination of veliparib and carboplatin added to standard chemotherapy increase pCR rates in TNBC.

Rucaparib is also one of the PARP inhibitor and its function is to repair DNA and maintaining genomic stability (Colombo et al., 2018). A multicentre trial was administered and it shows that rucaparib can inhibit PARP even at a minimum concentration. Based on the result, overall response rate of $41 \%$ with 12 week progression free survival is achieved (Drew et al., 2016). Another multicentre study was conducted to test the rucaparib efficiency in patients with HER- metastatic breast cancer. The clinical outcomes of this research is to obtain clinical benefit rate, longer PFS, overall survival and the prognostic biomarker of BRCA (Patsouris et al., 2017).

\section{Mammalian target of rapamycin (mTOR) inhibitor}

The signalling pathway is activated by receptor tyrosine kinase, which will have triggered the activation of PI3K followed by phosphorylation of AKT and mTOR complex. The activation of PI3K/AKT/mTOR pathway can occur due to overexpression of upstream regulator (EGFR) or loss of expression of phosphate and tensin homolog (PTEN) (Costa et al., 2018). There is high incidence of PTEN loss and mTOR activation in TNBC (Wahba \& El-Hadaad 2015). Inhibiting mTOR signalling pathway will terminate cellular proliferative responses and lead to cell cycle arrest (O'Reilly et al., 2015). Inhibiting mTOR is also beneficial for TNBC subtype mesenchymal and mesenchymal stem- like due to the presence of high expression of growth factor signalling receptor (Peddi et al., 2012). Thus, by inhibiting the mTOR will be beneficial for treatment of TNBC. 
Everolimus is one of the mTOr inhibitor approved for the treatment of cancer. A phase I trial was conducted to test the efficacy of combining everolimus with chemotherapy drug eribulin in metastatic TNBC. 27 patients were enrolled and have been treated with combination of everolimus and eribulin. Positive result was obtained with 2.6 months of median progression free survival and 8.3 months overall survival (Lee et al., 2019). (Singh et al., 2014) also investigated the effects of everolimus with chemotherapy drug carboplatin in phase II clinical study for metastatic TNBC. The study recorded efficacy in progression free survival for 3 months with clinical benefit rate of $36 \%$, that shows the treatment was efficacious in metastatic TNBC.

\section{Androgen receptor}

Tnbc with luminal androgen receptor subtype is a subtype that enriched with androgen receptor expression (Lehmann et al., 2011). Androgen receptors are necessary for normal breast development but their dysregulation may risk in breast tumorigenesis. It may regulate genes involved in metastasis and developed independent tumorigenic activity. Even though it demonstrated tumorigenic activity, preclinical study shows that the interaction between androgen receptors and estrogen receptors may inhibit tumor growth. However, in TNBC estrogen receptors are absence thus androgen receptors continue to stimulate tumor cell growth (Mina, Yoder, \& Sharma, 2017). The role of androgen receptor as TNBC treatment is still not clear as androgen receptor seems to retain oncogenic effect, thus prognostic value of androgen receptor becomes controversial (Mrklić, Pogorelić, Ćapkun, \& Tomić, 2013). However, recent studies proves this subtype respond to antiandrogen therapies as alternative of chemotherapy free treatment for TNBC.

The efficacy of these strategies has been investigated in clinical trial, which may shed some light to androgen receptor targeted therapy. The first clinical study for anti androgen therapy for breast cancer was reported by (Gucalp et al., 2013). A single arm study was performed to androgen receptor positive and estrogen receptor negative breast cancer patients. Bicalutamide at the dose of $150 \mathrm{mg}$ was administered orally on a continuous daily schedule to the patients. Bicalutamide is an oral nonsteroidal androgen receptor antagonist. The finding records $19 \%$ of clinical benefit rate and longer median progression free survival for at least 6 months. It can be concluded that the bicalutamide treatment was well tolerated for androgen receptor positive with moderate toxicity effect to patients.

Another phase II trial, evaluating new anti androgen receptor which is enzalutamide. Enzalutamide is antiandrogen that inhibit androgen receptor signalling pathway which will prevent transcription of androgen responsives gene (Nadal $\&$ Bellmunt, 2016). In this study 118 patients were received enzalutamide 160mg once per day until disease progression. Of 118 patients 78 patients were TNBC. Clinical benefit rate at primary end point (16 weeks) was 33\% and secondary endpoint ( 24 weeks) was $28 \%$. The study recorded longer median progression free survival of 3.3 months with overall survival of 17.6 months. Enzalutamide treatment demonstrated positive clinical response in TNBC treatment with minimum side effect to patients (Traina et al., 2018).

\section{Epidermal growth faactor receptor (EGFR)}

Numerous cases of TNBC are overexpression of EGFR (Masuda et al., 2012). EGFR is a cell surface transmembrane tyrosine kinase receptor, encoded by the cell erythroblastosis virus oncogene B1 (C-erbB1) and a part of the HER/erythroblastosis virus oncogene B (ErbB) family (Jamdade et al., 2015). It comprises of the extracellular space, transmembrane space and intracellular tyrosine kinase space. EGFR plays role in cellular processes such as signalling, proliferation, differentiation and cell development (Yano et al., 2003). Overexpression of EGFR is often associated with the cause of many human epithelial cancers such as breast cancer, lung, pancreatic and brain cancer (Changavi et al., 2015). These receptors receive signals that promote cancer growth upon activation, leading to cell proliferation, angiogenesis, and metastasis, and decreased apoptosis (Baselga, 2002). This overexpression of EGFR lead to tumor progression, resistance to chemotherapy and poor prognosis. (Yang et al., 2010).

EGFR is activated by binding of its specific ligands such as epidermal growth factor (EGF). This leads to receptor dimerization followed by kinase activation and trans phosphorylation of residues in the intracellular domain. This will lead to activation of adaptor and enzyme to stimulate their corresponding signalling pathway. This pathway than will activated many biological outputs that are beneficial for growth of cancer cells (Seshacharyulu et al., 2012). Anti-EGFR therapy is an attractive target and play significant role in the treatment of cancer to restrain EGFR signalling pathway (Zakaria et al., 2019). This anti-EGFR will bind to the EGFR to block ligand binding and block the activity of EGFR. The growth signals cannot bind to EGFR and therefore cannot promote cell growth (Nakai et al., 2016; Kim et al., 2017). Thus, EGFR-targeted therapy might have a promising role in TNBC.

Cetuximab and panitumumab are monoclonal antibodies, which are commonly used in cancer treatment. They will bind to EGFR and prevent the binding of EGF thus inhibits EGFR-dependent signalling pathways during cell division in the G1 phase, which leads to cell apoptosis (Chacón \& Costanzo, 2010; Holubec, Polivka, Safanda, Karas, \& Liska, 2016). (Cowherd et al., 2015) conducted phase II clinical trial in metastatic TNBC patients to evaluate the combination of chemotherapy drug paclitaxel and carboplatin with panitumumab. The result recorded overall response rate of $46 \%$ and longer median progression free survival of 3.6 months. The combination treatment shows positive clinical response in TNBC treatment.

Another phase II clinical trial conducted to investigate combination of cetuximab with docetaxel for stage II-III TNBC patients. The treatment consists of weekly cetuximab infusion combined with 6 cycle of docetaxel once every 3 weeks. The primary endpoint of this study was pCR rate which was $24 \%$. While the secondary endpoint of this study was 
clinical response which recorded complete clinical response in $22 \%$ of cases. Cetuximab in combination with docetacel shows decent therapeutic effect with acceptable toxicity effects (Nabholtz et al., 2016).

Table 3. Clinical trial in TNBC treatment

\begin{tabular}{|c|c|c|c|c|}
\hline Study Design & $\begin{array}{l}\text { Patient } \\
\text { Population }\end{array}$ & Treatments & Patients, $\mathrm{n}$ & Results \\
\hline \multicolumn{5}{|l|}{ PARP inhibitor } \\
\hline $\begin{array}{l}\text { Randomized, } \\
\text { Phase III } \\
\text { (Robson et al., 2017) }\end{array}$ & $\begin{array}{l}\text { BRCA mutation, } \\
\text { HER 2- breast } \\
\text { cancer }\end{array}$ & Oliparib vs chemotherapy & 205 vs 97 & $\begin{array}{l}\text { PFS: } 7 \text { vs } 4.2 \text { months } \\
\text { ORR: } 59.9 \% \text { vs } 28.8 \%\end{array}$ \\
\hline $\begin{array}{l}\text { Open label, Phase II } \\
\text { (Rugo et al., 2016) }\end{array}$ & TNBC & $\begin{array}{l}\text { Veliparib+Carboplatin+chemotherapy } \\
\text { vs chemotherapy }\end{array}$ & 72 vs 44 & pCR: $52 \%$ vs $26 \%$ \\
\hline $\begin{array}{l}\text { Open label, Phase II } \\
\text { (Drew et al., 2016) }\end{array}$ & $\begin{array}{l}\text { BRCA1/2 } \\
\text { mutation }\end{array}$ & Rucaparib & 78 & $\begin{array}{l}\text { PFS: }>12 w \\
\text { ORR: } 41 \%\end{array}$ \\
\hline \multicolumn{5}{|l|}{ MTOR } \\
\hline $\begin{array}{l}\text { Phase } 1 \\
\text { (Lee et al., 2019) }\end{array}$ & Metastatic TNBC & Everolimus+eribulin & 27 & $\begin{array}{l}\text { PFS: } 2.6 \text { months } \\
\text { OS: } 8.3 \text { months }\end{array}$ \\
\hline $\begin{array}{l}\text { Phase II } \\
\text { (Singh et al., 2014) }\end{array}$ & Metastatic TNBC & Everolimus+carboplatin & 25 & $\begin{array}{l}\text { PFS: } 3 \text { months } \\
\text { CBR: } 36 \%\end{array}$ \\
\hline \multicolumn{5}{|l|}{ Androgen receptor } \\
\hline $\begin{array}{l}\text { Phase II } \\
\text { (Gucalp et al., 2013) }\end{array}$ & $\begin{array}{l}\text { Androgen } \\
\text { receptor + breast } \\
\text { cancer } \\
\text { Estrogen - breast } \\
\text { cancer }\end{array}$ & Bicalutamide & 424 & $\begin{array}{l}\text { PFS: } 6 \text { months } \\
\text { CBR: } 19 \%\end{array}$ \\
\hline $\begin{array}{l}\text { Phase II } \\
\text { (Traina et al., 2018) }\end{array}$ & TNBC & Enzalutamide & 78 & $\begin{array}{l}\text { PFS: } 3.3 \text { months } \\
\text { CBR: } 33 \%(16 w) \\
28 \%(24 w) \\
\text { OS: } 17.6 \%\end{array}$ \\
\hline \multicolumn{5}{|l|}{ EGFR } \\
\hline $\begin{array}{l}\text { Phase II } \\
\text { (Cowherd et al., 2015) }\end{array}$ & $\begin{array}{l}\text { Metastatic TNBC } \\
\text { Locally advance } \\
\text { TNBC }\end{array}$ & Panitumumab+paclitaxel+carboplatin & 14 & $\begin{array}{l}\text { PFS: } 3.6 \text { months } \\
\text { ORR: } 46 \%\end{array}$ \\
\hline $\begin{array}{l}\text { Phase II } \\
\text { (Nabholtz et al., 2016) }\end{array}$ & Stage II,III TNBC & Cetuximab+docetaxel & 33 & pCR: $24 \%$ \\
\hline
\end{tabular}

$\mathrm{N}$, number of patients; ORR, overall response rate; PFS, progression free-survival; CBR, clinical benefit rate; OS, overall survival.

\section{CONCLUSION}

Lack of targeted therapy and standard treatment lead to mortality of TNBC. For now, chemotherapy becomes a common treatment for TNBC, however the result does not improve overall response rate and progression free survival as compared to the other type of cancer. As the disease itself is complicated, research to find new therapeutic approach also becoming complex. This review focuses on the potential target for TNBC. It is important to understand which target can benefit the therapeutic effect to TNBC. The outcome from clinical trials using inhibitor that target specific subtype of TNBC, shows promising result in treatment of TNBC. Currently there are more ongoing clinical study and hopefully will improve paradigm of TNBC treatment. So that in the future TNBC patients may gain benefit from chemotherapy or treatment.

\section{ACKNOWLEDGMENT}

This work was financially supported by a Research Grant (Project No. RDU150379 and RDU1803181) from University Malaysia Pahang (www.ump.edu.my) and Fundamental Research Grant Scheme (FRGS/1/2017/TK05/UMP//1, RDU170130) from Ministry of Higher Education (MoHE), Malaysia for which the authors are very grateful.

\section{REFERENCES}

Ahn, S. G., Kim, S. J., Kim, C., \& Jeong, J. (2016). Molecular Classification of Triple-Negative Breast Cancer. Journal of Breast Cancer, 19(3), 223-230. https://doi.org/10.4048/jbc.2016.19.3.223

Baselga, J. (2002). Why the epidermal growth factor receptor? The rationale for cancer therapy. The Oncologist, 7 Suppl 4(Supplement 4), 2-8. https://doi.org/10.1634/THEONCOLOGIST.7-SUPPL_4-2

Bollinger, S., Warren, G., Gehlert, S., Auslander, W., Edmond, T., Margenthaler, J., ... Louis, S. (2013). An Exploration 
of the Lives of Young, African American Women with Triple-Negative Breast Cancer. Retrieved from http://openscholarship.wustl.edu/etd

Chacón, R. D., \& Costanzo, M. V. (2010). Triple-negative breast cancer. Breast Cancer Research, 12 (S2), S3. https://doi.org/10.1186/bcr2574

Changavi, A., Shashikala, A., \& Ramji, A. (2015). Epidermal growth factor receptor expression in triple negative and nontriple negative breast carcinomas. Journal of Laboratory Physicians, 7(2), 79. https://doi.org/10.4103/09742727.163129

Colombo, I., Lheureux, S., \& Oza, A. M. (2018). Rucaparib: a novel PARP inhibitor for BRCA advanced ovarian cancer. Drug Design, Development and Therapy, Volume 12, 605-617. https://doi.org/10.2147/DDDT.S130809

Costa, R. L. B., Han, H. S., \& Gradishar, W. J. (2018). Targeting the PI3K/AKT/mTOR pathway in triple-negative breast cancer: a review. Breast Cancer Research and Treatment, 169(3), 397-406. https://doi.org/10.1007/s10549-0184697-y

Cowherd, S., Miller, L. D., Melin, S. A., Akman, S., Isom, S., Cole, J., ... Lawrence, J. A. (2015). A phase II clinical trial of weekly paclitaxel and carboplatin in combination with panitumumab in metastatic triple negative breast cancer. Cancer Biology \& Therapy, 16(5), 678-683. https://doi.org/10.1080/15384047.2015.1026481

Dai, X., Xiang, L., Li, T., \& Bai, Z. (2016). Cancer hallmarks, biomarkers and breast cancer molecular subtypes. Journal of Cancer, 7(10), 1281-1294. https://doi.org/10.7150/jca.13141

Desroches, J., Champagne, P. A., Benhassine, Y., Paquin, J.-F., Lukacs, M., \& Bhadra, D. (2015). Molecular Profiling of Acquired Resistance to Chemotherapy in Triple Negative Breast Cancer Cell Lines. Org. Biomol. Chem., 13(8), 2243-2246. https://doi.org/10.1002/ejoc.201200111

Dias, K., Dvorkin-Gheva, A., Hallett, R. M., Wu, Y., Hassell, J., Pond, G. R., .. Bane, A. L. (2017). Claudin-low breast cancer; clinical \& pathological characteristics. PLoS ONE, 12(1), 1-17. https://doi.org/10.1371/journal.pone.0168669

Drew, Y., Ledermann, J., Hall, G., Rea, D., Glasspool, R., Highley, M., ... Plummer, R. (2016). Phase 2 multicentre trial investigating intermittent and continuous dosing schedules of the poly(ADP-ribose) polymerase inhibitor rucaparib in germline BRCA mutation carriers with advanced ovarian and breast cancer. British Journal of Cancer, 114(7), 723-730. https://doi.org/10.1038/bjc.2016.41

Gucalp, A., Tolaney, S., Isakoff, S. J., Ingle, J. N., Liu, M. C., Carey, L. A., ... Translational Breast Cancer Research Consortium (TBCRC 011). (2013). Phase II trial of bicalutamide in patients with androgen receptor-positive, estrogen receptor-negative metastatic Breast Cancer. Clinical Cancer Research: An Official Journal of the American Association for Cancer Research, 19(19), 5505-5512. https://doi.org/10.1158/1078-0432.CCR-12-3327

Holubec, L., Polivka, J., Safanda, M., Karas, M., \& Liska, V. (2016). The Role of Cetuximab in the Induction of Anticancer Immune Response in Colorectal Cancer Treatment. Anticancer Research, 36(9), 4421-4426. https://doi.org/10.21873/anticanres.10985

Ismail-Khan, R., \& Bui, M. M. (2010). A review of triple-negative breast cancer. Cancer Control, 17(3), $173-176$. https://doi.org/10.1177/107327481001700305

Jamdade, V. S., Sethi, N., Mundhe, N. A., Kumar, P., Lahkar, M., \& Sinha, N. (2015). Therapeutic targets of triplenegative breast cancer: A review. British Journal of Pharmacology, 172(17), $4228-4237$. https://doi.org/10.1111/bph.13211

Jhan, J.-R., \& Andrechek, E. R. (2017). Triple-negative breast cancer and the potential for targeted therapy. Pharmacogenomics, 18(17), 1595-1609. https://doi.org/10.2217/pgs-2017-0117

Johnson, R., Sabnis, N., McConathy, W. J., \& Lacko, A. G. (2013). The potential role of nanotechnology in therapeutic approaches for triple negative breast cancer. Pharmaceutics, 5(2), 353-370. https://doi.org/10.3390/pharmaceutics5020353

Kim, B. J., Jeong, J. H., Kim, H. S., \& Kim, J. H. (2017). The role of anti-EGFR agents in patients with locoregionally advanced head and neck cancer: a meta-analysis of randomized trials. Oncotarget, 8(60), 102371-102380. https://doi.org/10.18632/oncotarget.21987

Kondov, B., Milenkovikj, Z., Kondov, G., Petrushevska, G., Basheska, N., Bogdanovska-Todorovska, M., ... Ivkovski, L. (2018). Presentation of the molecular subtypes of breast cancer detected by immunohistochemistry in surgically treated patients. Open Access Macedonian Journal of Medical Sciences, 6(6), 961-967. https://doi.org/10.3889/oamjms.2018.231

Kutty, R. V., \& Feng, S.-S. (2013). Cetuximab conjugated vitamin E TPGS micelles for targeted delivery of docetaxel for treatment of triple negative breast cancers. Biomaterials, 34(38), 10160-10171.

Lebert, J. M., Lester, R., Powell, E., Seal, M., \& McCarthy, J. (2018). Advances in the systemic treatment of triplenegative breast cancer. Current Oncology, 25(June), S142-S150. https://doi.org/10.3747/co.25.3954

Lee, J. S., Yost, S. E., Blanchard, S., Schmolze, D., Yin, H. H., Pillai, R., ... Yuan, Y. (2019). Phase I clinical trial of the combination of eribulin and everolimus in patients with metastatic triple-negative breast cancer. Breast Cancer Research, 21(1), 1-13. https://doi.org/10.1186/s13058-019-1202-4

Lehmann, B. D., Bauer, J. A., Chen, X., Sanders, M. E., Chakravarthy, A. B., Shyr, Y., \& Pietenpol, J. A. (2011). Identification of human triple-negative breast cancer subtypes and preclinical models for selection of targeted therapies. The Journal of Clinical ..., 121(7), 2750. https://doi.org/10.1172/JCI45014DS1

Mahfoudh, W., Bettaieb, I., Ghedira, R., Snoussi, K., Bouzid, N., Klayech, Z., ... Zakhama, A. (2019). Contribution of BRCA1 5382insC mutation in triple negative breast cancer in Tunisia. Journal of Translational Medicine, 17(1), 
1-5. https://doi.org/10.1186/s12967-019-1873-8

Masuda, H., Zhang, D., Bartholomeusz, C., Doihara, H., Hortobagyi, G. N., \& Ueno, N. T. (2012). Role of epidermal growth factor receptor in breast cancer. Breast Cancer Research and Treatment, 136(2), 331-345. https://doi.org/10.1007/s10549-012-2289-9

Mehanna, J., Haddad, F. G. H., Eid, R., Lambertini, M., \& Kourie, H. R. (2019). Triple-negative breast cancer: Current perspective on the evolving therapeutic landscape. International Journal of Women's Health, 11, 431-437. https://doi.org/10.2147/IJWH.S178349

Mina, A., Yoder, R., \& Sharma, P. (2017). Targeting the androgen receptor in triple-negative breast cancer: Current perspectives. OncoTargets and Therapy, 10, 4675-4685. https://doi.org/10.2147/OTT.S126051

Mrklić, I., Pogorelić, Z., Ćapkun, V., \& Tomić, S. Ž. (2013). Expression of androgen receptors in triple negative breast carcinomas. Acta Histochemica, 115(4), 344-348. https://doi.org/10.1016/j.acthis.2012.09.006

Nabholtz, J. M., Chalabi, N., Radosevic-Robin, N., Dauplat, M. M., Mouret-Reynier, M. A., Van Praagh, I., ... PenaultLlorca, F. (2016). Multicentric neoadjuvant pilot Phase II study of cetuximab combined with docetaxel in operable triple negative breast cancer. International Journal of Cancer, 138(9), 2274-2280. https://doi.org/10.1002/ijc.29952

Nadal, R., \& Bellmunt, J. (2016). The evolving role of enzalutamide on the treatment of prostate cancer. Future Oncology, 12(5), 607-616. https://doi.org/10.2217/fon.15.351

Nakai, K., Hung, M.-C., \& Yamaguchi, H. (2016). A perspective on anti-EGFR therapies targeting triple-negative breast cancer. American Journal of Cancer Research, 6(8), 1609-1623. Retrieved from http://www.ncbi.nlm.nih.gov/pubmed/27648353

O’Reilly, E. A., Gubbins, L., Sharma, S., Tully, R., Guang, M. H. Z., Weiner-Gorzel, K., ... McCann, A. (2015). The fate of chemoresistance in triple negative breast cancer (TNBC). BBA Clinical, 3, $257-275$. https://doi.org/10.1016/J.BBACLI.2015.03.003

Patsouris, A., Vicier, C., Campion, L., Gouraud, W., Jimenez, M., Pezzella, V., ... Andre, F. (2017). An open-label, phase II study of rucaparib, a PARP inhibitor, in HER2- metastatic breast cancer patients with high genomic loss of heterozygosity: RUBY. Journal of Clinical Oncology, 35(15_suppl), TPS1117-TPS1117. https://doi.org/10.1200/JCO.2017.35.15_suppl.TPS1117

Peddi, P. F., Ellis, M. J., \& Ma, C. (2012). Molecular Basis of Triple Negative Breast Cancer and Implications for Therapy. International Journal of Breast Cancer, 2012, 1-7. https://doi.org/10.1155/2012/217185

Penault-Llorca, F., \& Viale, G. (2012). Pathological and molecular diagnosis of triple-negative breast cancer: A clinical perspective. Annals of Oncology, 23(SUPPL. 6), 22-25. https://doi.org/10.1093/annonc/mds190

Prasad, S., Efird, J. T., James, S. E., Walker, P. R., Zagar, T. M., \& Biswas, T. (2016). Failure patterns and survival outcomes in triple negative breast cancer (TNBC): a 15 year comparison of 448 non-Hispanic black and white women. SpringerPlus, 5(1), 756. https://doi.org/10.1186/s40064-016-2444-6

Robson, M., Im, S. A., Senkus, E., Xu, B., Domchek, S. M., Masuda, N., ... Conte, P. (2017). Olaparib for metastatic breast cancer in patients with a germline BRCA mutation. New England Journal of Medicine, 377(6), 523-533. https://doi.org/10.1056/NEJMoa1706450

Rugo, H. S., Olopade, O. I., DeMichele, A., Yau, C., van ’t Veer, L. J., Buxton, M. B., ... I-SPY 2 Investigators. (2016). Adaptive Randomization of Veliparib-Carboplatin Treatment in Breast Cancer. New England Journal of Medicine, 375(1), 23-34. https://doi.org/10.1056/NEJMoa1513749

Seshacharyulu, P., Ponnusamy, M. P., Haridas, D., Jain, M., Ganti, A. K., \& Batra, S. K. (2012). Targeting the EGFR signaling pathway in cancer therapy. Expert Opinion on Therapeutic Targets, 16(1), 15-31. https://doi.org/10.1517/14728222.2011.648617

Singh, J. C., Novik, Y., Stein, S., Volm, M., Meyers, M., Smith, J., ... Tiersten, A. (2014). Phase 2 trial of everolimus and carboplatin combination in patients with triple negative metastatic breast cancer. Breast Cancer Research, 16(2), 3389. https://doi.org/10.1186/bcr3634

Traina, T. A., Miller, K., Yardley, D. A., Eakle, J., Schwartzberg, L. S., O’Shaughnessy, J., ... Cortes, J. (2018). Enzalutamide for the Treatment of Androgen Receptor-Expressing Triple-Negative Breast Cancer. Journal of Clinical Oncology: Official Journal of the American Society of Clinical Oncology, 36(9), 884-890. https://doi.org/10.1200/JCO.2016.71.3495

Wahba, H. A., \& El-Hadaad, H. A. (2015). Current approaches in treatment of triple-negative breast cancer. Cancer Biology \& Medicine, 12(2), 106-116. https://doi.org/10.7497/j.issn.2095-3941.2015.0030

Yang, H., Park, C. W., Woo, M., Kim, M. Il, Jo, Y. M., Park, H. G., \& Kim, J. (2010). HER2 / neu Antibody Conjugated Poly ( amino acid ) -Coated Iron Oxide Nanoparticles for Breast Cancer MR Imaging, 2866-2872.

Yano, S., Kondo, K., Yamaguchi, M., Richmond, G., Hutchison, M., Wakeling, A., ... Wadsworth, P. (2003). Distribution and function of EGFR in human tissue and the effect of EGFR tyrosine kinase inhibition. Anticancer Research, 23(5A), 3639-3650. Retrieved from http://www.ncbi.nlm.nih.gov/pubmed/14666659

Zakaria, Z., Zulkifle, M. F., Hasan, W. A. N. W., Azhari, A. K., Raub, S. H. A., Eswaran, J., ... Syed Husain, S. N. A. (2019). Epidermal growth factor receptor (EGFR) gene alteration and protein overexpression in Malaysian triplenegative breast cancer (TNBC) cohort. OncoTargets and Therapy, 12, 7749-7756. https://doi.org/10.2147/OTT.S214611 